\title{
Work Engagement among Women Engineers in Malaysia
}

\author{
Siti Aisyah Panatik, Zairus Norsiah Azhar, Ungku Norulkamar Ungku Ahmad \& Hapriza Ashari
}

\begin{abstract}
This research aims to examine the effects of EffortReward Imbalance on work engagement among women engineers in Malaysia. In this study we review the Effort-Reward Imbalance (ERI) model as the psychosocial work environment that consisted of three distinct dimensions, namely effort, reward and over-commitment. In this study, a total of 300 questionnaires were distributed to women engineers, but only 250 questionnaires have been completed by the respondents. The data were analyzed using correlation and multiple regression through SPSS version 22. The findings showed that all the three dimensions of ERI model (i.e. effort, rewards, and over commitment) are related to work engagement among women engineers. This study indicated that reward is the most dominant influence work engagement among women engineers. This paper discusses the implication of this study in the context of literature and suggests strategies to improve workplace engagement.
\end{abstract}

\section{Keywords-ERI Model; Work engagement; Women Engineer}

\section{INTRODUCTION}

In a global economy, workplace can be characterized by job insecurity, forced occupational mobility, short-term contracts and increased wage competition. The contemporary organizations need employees who are psychologically connected to their work; who are willing and able to devote themselves fully in their works, proactive and committed to high quality performance standard [7]. Researchers currently gained attention to the importance of work engagement, which is one of the positive organizational behaviors construct that can be defined as a positive, fulfilling and work-related state of mind that is characterized by three components namely vigor, dedication, and absorption [5]. Previous research has consistently shown that job resources such as social support from colleagues and supervisors, performance feedback, skill variety, autonomy and learning opportunities are positively linked with work engagement [3].

Siti Aisyah Panatik ${ }^{1}$, Ungku Norulkamar Ungku Ahmad, Hapriza Ashari Faculty of Management, Universiti Teknologi Malaysia,

Johor Bahru, Johor Malaysia

Norzairus Norsiah Azhar

Language Academy, Universiti Teknologi Malaysia,

Johor Bahru, Johor Malaysia
Work engagement is essential in order to retain employees in the organization, especially organization within science, technology and engineering field. It is one of the Malaysian visions to be a fully developed country by the year 2020 . Among the challenges to achieve this vision is to establish a scientific and progressive society which is innovative and forward looking. Instead of just being consumer of technology, Malaysia aims to be a contributor to the scientific and technological civilization of the future. In line with this, Malaysian Ministry of Science, Technology and Innovation (MOSTI) in their policy for the 21 st century has specifically construct an objective of achieving a competent workforce of at least 60 RSEs (researchers, scientists and engineers) per 10,000 labor force by year 2010 in order to enhance national capability in science and technology (S\&T) (Malaysia's S\&T Policy for the 21st century, MOSTI). In addition, Malaysia also has a challenge of ensuring an economically just society, a society where there is an equitable distribution of the wealth of the nation. Empowerment of women has been made a fair key agenda in the Tenth Malaysia Plan of which women should be made to continue to be a primary force in contributing to the nation's economic growth. For this to happen, it is imperative to realize women's full potential to participate more effectively in the social development and other various fields in supporting the country's agenda in attaining global competitiveness.

However, according to the Malaysia Economic Report $2013 / 2014$, the rate of women participation in the work force is still low, not in tandem with the growth of the country's socioeconomic development. On top of that, women remain to be under represented in the engineering profession, most critical area in the nation wealth generation endeavor. Even though there is an increase rate of women in the labor force today, about 70 percent of those who have science, engineering and technology related degrees were not working in the technical field (Ministry of Women, Family and Community Development, Malaysia, 2010). As noted by many studies, women engineers face close-to insurmountable difficulties in the field of engineering such as low opportunities in career opportunities and advancement, received lower pay and benefit than male colleagues [19]. In addition, women engineers also get a less challenging assignment than their male counterparts [1]. This phenomenon showed that women engineer experienced 'imbalance' or unfairness in technical field. Therefore, the rate of woman engineers leaving the profession is high.

Based on the previous research, the current study used the Effort-Reward Imbalance (ERI) model to explain the roles of 
intrinsic and extrinsic motivation in predicting the persistence of women in the engineering field. The ERI model is based on the principle of reciprocity that focus on the effort of employee spent at work and reward they receive. According to the model, the experience of a lack of reciprocity in term of high costs and low gains may elicit emotional distress and job strain in exposed people [12]. While there are studies examining this shortage [10], few studies that have investigated the pulling factor that attract women to the engineering profession and what keep them actively engaged in this field. Therefore, the objective of this study is to investigate on how the effortrewards imbalance influences work engagement among woman engineers in Malaysia.

\section{LITERATURE REVIEW}

\section{A. The Effort-reward imbalance (ERI) model}

The Effort-Reward Imbalance (ERI) model was introduced by Siegriest et. al. [11]. It is one of the most important models in the occupational health research to explain the role of social and psychological factors in human health and disease. The ERI model is based on the principle of reciprocity that focus on the effort of the employee put at work and reward they receive. The ERI model claims that lack of reciprocity between effort and reward may elicit emotional distress and job strain [12].

The ERI model comprises of three distinct dimensions which are efforts, rewards and over-commitment. The effort (job demands and work obligation) and reward (money, esteem and career opportunities) represents the extrinsic source while over commitment represents an intrinsic source. ERI model also has further predicted that an employee who is highly committed to their job tends to be more experience of the imbalance of effort and reward [15].

A previous study has found that perception of imbalance leads to health such as cardiovascular diseases and psychiatric disorders [11]. Furthermore, the model can be applied to addictive behavior such as alcoholism. Recently, this model has extended the interest to outcomes that are not linked with health such as job satisfaction, burnout [2], and work-life conflict [16]. However, the idea prevails that people will not passively stay in a high effort and low reward situations because they will try reducing their effort and/or maximizing their reward [15]. Hence, an ERI might not influence health for a long period.

Besides, Siegrist [11] identified some specific situational factor that high cost and low gain condition is maintained; (1) when there is no alternative choice on the labor market, (2) for strategic reasons such as expecting future gains/rewards (3) when the employee is characterized as an over committed person. Over commitment can be defined as "a set of attitudes, behaviors and emotions that reflect excessive striving in combination with a strong desire to approved and esteemed.

Based on the ERI model depicted in Fig. 1, there are three hypotheses that have been derived from the model [11]. First, imbalance reciprocity between effort and reward increases the risk of poor health (extrinsic ERI hypothesis). Second, overcommitted people with low reward are more prone to adverse health than the less committed person that in the same situation (intrinsic over commitment hypothesis). Third, people that perceive an imbalance between effort and reward combine with high level of commitment are more exposed to poor health (interaction hypothesis).

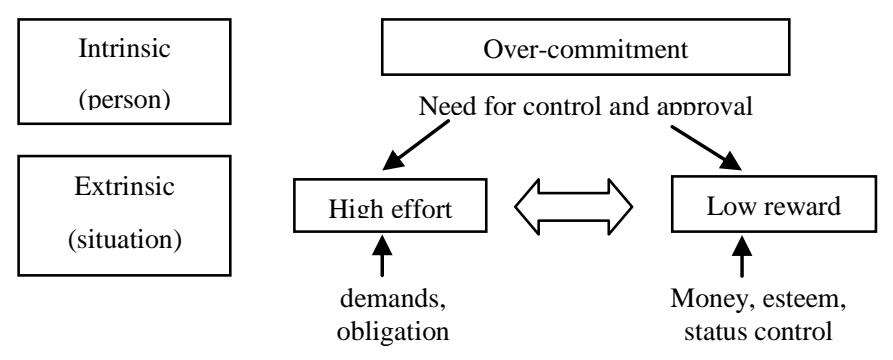

Fig. 1 Effort-reward Imbalance Model

Source: Siegrist (1999)

\section{B. Work Engagement}

Work engagement is one of the positive organizational behaviors. The concept was first introduced by Kahn [23] who defined engagement in term of personal engagement and disengagement. Personal engagement is described as the employing or expressing of oneself physically, cognitively and emotionally during work role performances. When engaged, an employee is characterized by physically involved, cognitively vigilant and emotionally attached.

Kahn [23] was the first to theorize work engagement, but Bakker and Schaufeli [5] has proposed the most frequently used explanation. Work engagement as a "positive, fulfilling and work-related state of mind that is characterized by vigor, dedication and absorption" [5]. Vigor refers to the feeling of energy and mental resilience while working. Dedication refers to being strongly involved and experienced a sense of significance, enthusiasm, pride and challenge while working. Absorption refers to being fully concentrated and happy while working. Therefore, engaged employees can be characterized as energetic, enthusiastic and fully attached to their job.

The antecedent and consequences of work engagement have been of subject interest research. Previous studies have consistently found that job resources and personal resources are the main predictors of work engagement [3][5][8]. Job resources refer to the physical, social or organizational aspects of the job that possibly will (1) reduce the job demands; (2) useful in accomplishing work goals; and (3) stimulate personal growth, learning and development [4]. The examples of job resources are social support, job autonomy, performance feedback and supervisory coaching. This job resource is reported becoming more salient when the job demands are high [3]. For example, past studies indicated that teachers are more engaged to their job when confronted with high misbehavior pupils at school [8]. 
Meanwhile, personal resource is a positive self-evaluation that refers to an individual's sense of their ability to control and impact on their environment [4]. Several studies also have found that personal resources linked positively with work engagement [5][8]. For example, a study by Xanthopoulou, Bakker, Demerouti and Schufeli [8] has found that three components of personal resources (self-efficacy, self-esteem and optimism) associated positively with work engagement among Dutch employees. Engaged employee were highly selfefficacious by believing that they manage to meet the demands. Engaged employee also more optimistic about their life and believe they able to satisfy their needs by participating in roles within the organization [8].

\section{Effort-reward imbalance and work engagement among women engineer}

Karasek's earlier Job Demand-Control (JDC) model focused on the external work characteristics of demand and the workers' level of control over them, Siegrist shifted the focus to the Effort-Reward Imbalance (ERI) model that emphasized the high cost and low gain at work. The perception of imbalance between effort-reward arises when effort that employees spent at work did not matched by adequate rewards. This imbalance hence causes emotional distress and job strain.

Most of the previous studies revealed that women engineer experienced 'imbalance' or unfairness [10][14]. For instance, they received marginalized roles, less challenging work, limited promotion and career opportunities [10]. Besides, several senior women engineers in a study by Roberts and Ayre [19] reported that they received lower salaries than male colleagues who were younger and less experienced. Moreover, the woman engineer reported that they perceive less support from their employers to help them balance the demand of work and home lives [14]. Woman engineer also claimed that they need a mentor to show them how to be women within the maledominated profession [10]. They also received low social support by not being accepted as a leader or manager and being excluded from workgroup social occasions [10]. This unfairness or 'imbalance' made woman engineer leaves the profession greater than men.

The relevance of the ERI to the work engagement is clear. It is predicted that the perceived of high cost/low gain and over commitment might result in an engagement or disengagement at work. It is also likely that women engineer who has put effort, but not received a proper promotion or career opportunities are expected to leave the engineering profession. Moreover, as numerous previous studies found that effortreward imbalance can result to negative reaction and job strain [2] [17], perceived unfairness could also lead to disengagement at work.

\section{Conceptual Framework}

Figure 2 shows the conceptual framework for this study. The effort-reward imbalance is taken as independent variable, whereas the dependent variable is work engagement. The effort-reward imbalance consists of three components namely effort, rewards and over commitment. Meanwhile, the work engagement consists of three components which are vigor, dedication and absorption.

\begin{tabular}{|l|c|}
\multicolumn{1}{|c|}{ Independent Variable } & Dependent Variable \\
\hline Effort-reward Imbalance & \\
- Effort & $\begin{array}{c}\text { Work Engagement } \\
\text { - Reward } \\
\text { - Over commitment }\end{array}$ \\
\cline { 2 - 2 } & - Vigor \\
& - Dedication \\
& - Absorption \\
\hline
\end{tabular}

Fig. 2 Conceptual framework of research

\section{METHODOLOGY}

\section{A. Participants}

A total of 250 full-time women engineers from various engineering discipline and sector in Malaysia participated in this study. Majority of the respondent were between the age ranges of 30-35 years old. The survey responses were strongly dominated by Malay (84\%), with only $9.2 \%$ Chinese, $3.6 \%$ Indians and $2 \%$ other ethnics. Most of the respondent were married (74.4\%) with children and parent as dependent responsibilities $(84.8 \%)$. Majority of the respondents were senior staff with 5 to 10 years of working experiences. $30.3 \%$ were practicing civil engineering and $18 \%$ were practicing electronic/electrical engineering. Most of the respondents were working in the public sector $(62.2 \%)$

\section{B. Data Collection Procedure}

This study utilized snowball technique method to gather the participant of this study. A snowball sampling is a method yields a study sample through referrals made among people who share or know of others who possess some characteristics that are of research interest [18]. Snowball sampling has the advantage to help the researcher to identify potential participants. Questionnaires were mailed to a few potential participants through the online Google document. Then, we recruited the participants to distribute the questionnaire to any employed woman engineer they think might be interested and qualified. Participants were voluntary and informed that their responses remain confidential.

\section{Measures}

The Effort-Reward Imbalance (ERI) Questionnaire developed by Siegrist, Li \& Montano [13] was used to measure extrinsic effort, rewards and over-commitment. A three items were used to measure effort (e.g., "I have constant time pressure due to a heavy workload"), a seven items to measure rewards (e.g., "My job promotion prospects are poor"), and a six items to measure over-commitment (e.g., "“I get easily overwhelmed by time pressures at work"). Items 
were scored on a five-point scale where $1=$ =strongly disagree, $2=$ disagree, $3=$ moderately agree, $4=$ agree, $5=$ strongly agree.

Meanwhile, the shortened-version of Work \& Well-being Survey (UWES) adapted by Schaufeli \& Bakker [22] was used to measure the respondent's work engagement. Three aspects of the work engagement have been measured in this study, namely, vigor, dedication and absorption. The sample items for work engagement are "At my work, I feel bursting with energy." (vigor), "I find the work that I do full of meaning and purpose" (dedication) and "I am immersed in my work" (absorption). A high score on all three construct indicate high work engagement. Items were scored on a scale ranging from (1) "strongly disagree" to (5) "strongly agree".

\section{Data Analysis}

All data were analyzed using descriptive statistics, correlation and inferential statistical analysis using Statistical Package for Social Sciences (SPSS).

\section{RESULT}

\section{A. The Level of Study Variables}

Table 1 presents the levels of each variable used in this study. Descriptive statistics such as mean and standard deviation were used to measure the level of effort-reward imbalance and work engagement. In overall, the respondents reported moderate mean score for both effort-reward imbalance $(m=3.25)$ and work engagement $(m=3.60)$. More specific for the ERI dimensions, the result showed that effort $(m=3.45)$ has the higher mean score compared to reward $(\mathrm{m}=3.24)$ and over commitment $(\mathrm{m}=3.07)$. This means the respondents perceived high level of effort, followed by reward and over-commitment. Meanwhile, the result of work engagement dimensions indicated that the level of dedication $(\mathrm{m}=3.72)$ is high compared to vigor $(m=3.55)$ and absorption $(m=3.54)$. This indicated that the respondent is highly dedicated to their work.

TABLE 1. THE LEVEL OF VARIABLE OF STUDY

\begin{tabular}{|l|c|c|c|}
\hline \multicolumn{1}{|c|}{ Variables } & Mean & $\begin{array}{c}\text { Standard } \\
\text { Deviation }\end{array}$ & Level \\
\hline ERI (Overall) & 3.25 & 0.57 & Moderate \\
\hline Effort & 3.45 & 0.73 & Moderate \\
\hline Reward & 3.24 & 0.56 & Moderate \\
\hline Over-commitment & 3.07 & 0.63 & Moderate \\
\hline $\begin{array}{l}\text { Work engagement } \\
\text { (overall) }\end{array}$ & 3.60 & 0.51 & Moderate \\
\hline Vigor & 3.55 & 0.58 & Moderate \\
\hline Dedication & 3.72 & 0.61 & High \\
\hline Absorption & 3.54 & 0.58 & Moderate \\
\hline
\end{tabular}

\section{DISCUSSION AND CONCLUSION}

The objective of this study is to investigate the effect of ERI components on work engagement. The findings showed that ERI among women engineers in Malaysia is at a moderate level. The finding also indicated that the components of the ERI show a relationship and an effect on the women engineers' work engagement. Regression analysis found that reward was the stronger predictor on work engagement. This shows that reward such as salary, career opportunities and job security is important predictor in motivating women engineers 
to strive in male-dominated field. This is line with the principle of social exchange/reciprocity whereby the employee devotes efforts and expects rewards in return.

Meanwhile, the over commitment and effort also have positive and significant effect on work engagement. Based on the previous study, women engineers try to put additional effort into their work in order to cope and gain better and more satisfying rewards [21]. This is because most of the women engineers experience unfairness in term of salary and opportunities than their male coworkers [14] [19]. Therefore, women engineers feel that they need to put more effort into their work than their male counterpart to prove their capability. Apart from that, the possible explanation of this finding is because of job and personal resources such as supervisor support and self-efficacy may foster the employee willingness to dedicate their efforts and abilities to the work task [4]. On the basis of the job demands-resources model, resources act as buffers and reduce the negative relationship between job demands and work engagement. For example, previous research by Bakker et al [3] found that supervisor support, innovativeness, appreciation, and organizational climate were important job resources that aided teachers to cope with misbehavior pupils.

In conclusion, this study revealed that the ERI components act as the predictor of work engagement in engineering sector, specifically in Malaysia setting. However, there are some limitations of this study that need to be mentioned. First, the data based on cross-sectional basis only. Thus, this study could not explore the long term effects of ERI on work engagement. Despite the limitation, this study provide information to the employer within engineering sector to provide equal opportunity to the women engineers so that they can capture talented women engineers to the industry. Future study should utilized longitudinal design to confirm the direction of ERI components and work engagement. Future study also should measure motivational factor that may moderate the relationship between effortreward imbalance and work engagement among the women engineer such as self-efficacy, supervisor support and performance feedback.

\section{Acknowledgment}

This work was supported by Universiti Teknologi Malaysia under FRGS Grant Nos. R.J130000.7829.4F572.

\section{References}

[1] A. Enshassi, S. Ihsen and K. Al Hallaq, "The perception of women engineers in the construction industry in Palestin," European Journal of Engineering Education, pp. 13-20, March 2008.

[2] A. B. Bakker, C. H. Killmer, J. Siegrist, and W. B. Schaufeli, "Effortreward imbalance and burnout among nurses," Journal of Advanced Nursing, vol. 31, pp. 884-891, April 2000.

[3] A. B. Bakker, J. J. Hakanen, E. Demerouti, E. and D. Xanthopoulou, "Job resources boost work engagement, particularly when job demands are high," Journal of Educational Psychology, vol. 99, pp. 274, October 2007.

[4] A. B. Bakker and E. Demerouti, "Towards a model of work engagement," Career Development International, vol. 13, pp. 209-223, 2008 .

[5] A. B. Bakker, W. B. Schaufeli, M. P. Leiter, M. P and T. W. Taris, "Work engagement: An emerging concept in occupational health psychology,” Work \& Stress, vol. 22, pp. 187-200, July 2008.

[6] A. B. Bakker and W. B. Schaufeli, "Positive organizational behavior: Engaged employees in flourishing organizations," Journal of Organizational Behavior, vol. 29, pp.147-154, January 2008.

[7] A. B. Bakker and M. P. Leiter, "Work engagement: A handbook of essential theory and research," Psychology Press, New York, 2010.

[8] D. Xanthopoulou, A. B. Bakker, E. Demerouti and W. B. Schaufeli, "The role of personal resources in the Job Demands-Resources model," International Journal of Stress Management, vol. 14, pp. 121-141, 2007.

[9] G. Kinman and J. Fiona, "Effort-reward imbalance, over-commitment and work-life conflict: testing an expanded model,"Journal of Managerial Psychology, vol. 23, April 2007.

[10] J. Mills, W. Bastalich, S. Franzway, J. Gill and R, Sharp, "Engineering in Australia: An uncomfortable experience for women," Journal of Women and Minorities in Science and Engineering, vol. 12, pp. 135$154,2006$.

[11] J. Siegrist, "Adverse health effects of high-effort/low-reward conditions," Journal Occupational Health Psychol, vol. 1, pp. 27-41., 1996

[12] J. Siegrist, J, "Effort-reward imbalance at work: Theory, measurement and evidence," Department of Medical Sociology, University Düsseldorf, Düsseldorf, November 2012.

[13] J. Siegrist, J. Li and D. Montano, "Psychometric properties of the effortreward imbalance questionnaire, June 2014.

[14] N. Fouad, M. Fitzpatrick and J. P. Liu, "Persistence of women in engineering careers: A qualitative study of current and former female engineers," Journal of Women and Minorities in Science and Engineering, vol. 17, pp. 69-96, June 2011.

[15] N. van Vegchel, J. de Jonge, H. Bosma and W. Schaufeli, "Reviewing the effort-reward imbalance model: drawing up the balance of 45 empirical studies," Social Science \& Medicine, vol. 60, pp. 1117-1131, March 2005.

[16] N. Heraty, M. J. Morley, J. N. Cleveland, G. Kinman and F. Jones, "Effort-reward imbalance, over-commitment and work-life conflict: testing an expanded model," Journal of Managerial Psychology, vol.23, pp. 236-251, 2008.

[17] O. von dem Knesebeck and J. Siegrist, J, "Reported nonreciprocity of social exchange and depressive symptoms: Extending the model of effort-reward imbalance beyond work," Journal of Psychosomatic Research, vol. 55, pp. 209-214, September 2003.

[18] P. Biernacki and D. Waldorf, "Snowball Sampling: Problems and Techniques of Chain Referral Sampling," Sociological Methods \& Research, vol. 10, pp. 141-163, 1981.

[19] P. Roberts and M. Arye, "Did she Jump or was she Pushed? A study of women's retention in the engineering workforce," International Journal OF Engineering Education, vol. 18, pp. 415-421, February 2002.

[20] S. Mauno, U. Kinnunen and M. Ruokolainen, "Job demands and resources as antecedents of work engagement: A longitudinal study," Journal of Vocational Behavior, vol. 70, pp. 149-171, 2007.

[21] T. Feldt, M. Huhtala, U. Kinnunen, K. Hyvönen, A. Mäkikangas and S. Sonnentag, "Long-term patterns of effort-reward imbalance and overcommitment: Investigating occupational well-being and recovery experiences as outcomes," Work \& Stress, vol. 27, pp. 64-87, February 2013.

[22] W. Schaufeli and A. Bakker, "UWES Utrecht Work Engagement Scale. Preliminary Manual, Version 1, November 2003

[23] W. A. Kahn, "Psychological conditions of personal engagement and disengagement at work," Academy of Management Journal, vol. 33, pp. 692-724, December 1990 . 